In a series of researches beginning in 1889 Hermann found that the analyses of phonograph curves showed the vowels to be constructed of puffs and inharmonics. He thus independently rediscovered the principle of Willis. This theory has been substantiated and developed by thousands of analyses in my work for the Carnegie Institution of Washington, and published in "The
Study of Speech Curves" (Carnegie Inst. Publ. No. 44), from which the above results are taken. It should be added that this extensive and somewhat expensive work was made possible by the support of Yale University and the liberality of the Carnegie Institution of Washington.

(To be continued.)

\title{
Nitrate Supplies and the Nitrogen Industry.
}

$\mathrm{T}^{\mathrm{H}}$ E Imperial Mineral Resources Bureau has recently issued a report on the nitrate industry of the British Empire and of foreign countries, containing all available statistics with regard to the production and prices of nitrates during the war period. In conjunction with this report may be considered a paper dealing with the nitrogen industry contributed by H. E. Fischer to the Journal of the Franklin Institute (August, 1920, vol. cxc., No. 2). This paper gives a comprehensive survey of the sources of the world's nitrogen supply, particularly as it affects America. Nitrogenous compounds are absolutely necessary to agriculture, to the manufacture of munitions, to refrigeration, and to the general applications of chemistry, and although nitrogen in its inert gaseous state forms fourfifths of the atmosphere, yet this is of no use for the above objects until it has been combined or "fixed" by some method.

In the combined form, nitrogen is found in Nature as mineral deposits, as organic compounds, and in carboniferous deposits. By far the most important of the mineral deposits are those of Chile. Before the war the greater part of the world's requirements in respect of nitrate and nitric nitrogen was met by the export of nitrate of soda from Chile. The Chilean nitrate industry is one of long standing, and expanded steadily from 100,000 tons per annum in the middle of the nineteenth century to $2,400,000$ tons in 1913 . It has been stated that the Chilean nitrate deposits are nearly exhausted, but according to the Chilean Nitrate Committee's report "there is no fear of the Chilean nitrate deposits being exhausted for 200 years." The nitrate occurs as scattered deposits in a formation known as caliche, consisting of a conglomerate of rock material cemented with a mixture of soluble salts, in which sodium chloride is the chief constituent as regards quantity, while sodium nitrate is second. It is only in scattered patches that the caliche contains nitrate in quantities large enough to warrant treatment. These patches are sought out and excavated, and the picked ore is hauled to the extraction plant, where the soluble salts are extracted in solution, and the nitrate is separated from the other salts by crystallisation.

A considerable amount of sodium nitrate is also produced in Egypt. For one company in I9r3 the output was 4740 metric tons, but the total output is not known definitely. In India potassium nitrate has been produced from very early NO. 2672 , VOL. IO6] times, but the trade has always been subject to great fluctuations. It attained its highest values during the American Civil War, for then India had practically a monopoly of the supplies of saltpetre needed for explosives. At that time the average aninual exports were 30,000 tons, but the development of the Chilean industry caused the Indian trade to decline, until in the years just before the war the exports were only I3,000 or 14,000 tons per annum. The war period again stimulated the trade, and in 1918 the output was 25,145 metric tons. The potassium nitrate is found in the soils of old villages, mixed with nitrates of calcium and magnesium and with sodium chloride. The process of extraction consists in dissolving out the mixed salts from the surface soil, roughly separating the sodium chloride and the potassium nitrate, and then purifying the nitrate.

Nitrogen compounds are also obtained as byproducts in a large number of industries. In dealing with animal, vegetable, and fish products, organic ammoniates are obtained, and these are left as such for use in agriculture, while from sources such as coal distillations, bone carbonisation, oil-shale distillation, and blast-furnace operations, nitrogen is recovered as ammonia and ammonium salts-chiefly ammonium sulphate, which is available in all capacities. The organic nitrogen recovered in these various by-product connections probably constitutes about 40 to 50 per cent. of the total supply, but this nitrogen has to compete for its market against the supplies of nitrates from natural sources and against those of synthetic nitrates, i.e. those obtained from combined atmospheric nitrogen.

As early as I78I Cavendish discovered that a nitric reaction was shown by water obtained by burning hydrogen in excess of air, and since his time very many chemists have studied the problem. In 1900 two Americans erected an experimental plant at Niagara for producing nitric acid from atmospheric nitrogen by means of a very high electric current, but this soon proved unremunerative and was abandoned. The luminous arc process for fixing atmospheric nitrogen was the first to be established commercially. In this process a dilute gaseous mixture of nitric oxides with air is obtained from the oxygen and nitrogen in the air; the nitric oxide is converted into nitric dioxide, and then absorbed in water to form nitric acid. It was started in Norway in 1903 , and, owing to the cheap horse-power there avail- 
able, and to the fact that the raw materials cost nothing and are always at hand, nitric acid can be produced there by the arc process at less cost than by any other commercial process. Efforts to introduce this process outside Norway have been unsatisfactory, partly because of its uneconomical use of power, and partly because of the difficulty in the subsequent handling of the end-product, a 30-35 per cent. acid against a 50-55 per cent. acid obtained by other processes.

The Haber process for ammonia synthesis was brought to a successful commercial stage in Germany in 1913, when the plant capacity was 30,000 tons of ammonium sulphate. In 1918 the output by this process was $\mathrm{r}, 060,000$ tons of ammonium sulphate. The process consists of forming ammonia by the direct combination, under the influence of a catalyser, of nitrogen from the air and hydrogen obtained from water. The production and purification of the hydrogen involve one of the chief items of cost in this process, but in spite of this the Haber is the cheapest process for the production of synthetic ammonia, and has the lowest power requirement of any of the nitrogen fixation methods.

In 1906 the calcium cyanamide process was successfully installed in Italy, and before the war it was also installed in Germany, Norway, France, Switzerland, the United States, Austria, Japan, and Sweden. The method is a complicated one, and involves a large number of stages, but it has developed extensively, because it requires only about one-fifth the horse-power per ton of fixed nitrogen per year that is required by the arc process, though five times that required by the Haber process.

Several other methods for nitrogen fixation are being experimented with, but they are not yet developed commercially. Mr. Fischer, after a full discussion, concludes that the result is that Germany can produce nitrates at one-half the cost in the United States, and, consequently, the German farmer can be supplied with fertilisers at one-half the cost to the American farmer. This is an enormous advantage to Germany, and if Germany succeeds in monopolising this industry -which she is in a position to do, barring internal disorders-she can either export nitrates at a price which will enable her to supply her farmers with fertilisers at a negligible cost, or undercut the price of nitrogenous products so that it will be unprofitable for the Chilean mines to continue working. Germany would thus in time indirectly control the world's production of explosives. Mr. Fischer therefore urges on the American people the importance of constructing plants for producing synthetic nitrates, by which means "our security would be vastly increased, the burden of obligation carried by our fleet would be greatly reduced, and its functional, effective value doubled."

\title{
Industrial Research Associations.
}

\author{
VIII.-The British Photographic Research Association.
}

\section{By Dr. T. Slater Price.}

THE British Photographic Research Association 1 was the first research association to be formed under the scheme of the Privy Council for the promotion of industrial and scientific research. Early in 1918 the manufacturers of photographic materials and apparatus decided to avail themselves of the scheme, and the research association was incorporated on May I5, 1918. The president of the association is Sir J. J. Thomson, and the chairman Mr. Gerald M. Bishop, of Messrs. Marion and Co., Ltd. The council of the association consists of representatives from the various sections of the industry, together with several well-known men of science, who are also represented on the list of vice-presidents. The first director of research was Dr. R. E. Slade, and laboratory accommodation was obtained in the chemical department of University College, Gower Street, where work was carried on until the end of September, r920. Owing to the large influx of students in the present session, however, it was necessary to vacate the laboratories at University College, and at the beginning of October the research association was transferred to the Institute of Chemistry, 30 Russell Square, W.C.I, where various rooms have been specially fitted and equipped for research work. In March, 1920, Dr. No. 2672 , VOL. IO6]
Slade resigned his position as director of research, and the present writer was appointed his successor, taking up his duties in the middle of September last.

As stated in the programme of research which has been issued, the object of the association is to carry out research in photography, photochemistry, and other related subjects with a view to the general increase of knowledge of the subjects, to improve methods of manufacturing photographic materials, and to discover new photographic processes. It is recognised that manufacturers will always insist on determining for themselves the lines on which their businesses shall develop, and the true aim of the association should be, by the proper application of scientific methods, to obtain knowledge which will be of the widest application to the industry, and which it will be left to each manufacturer to apply in his own way to the development of his business.

It is recognised not only that applied research should be undertaken in connection with the im. provement of products now being manufactured and of methods of manufacture, but also that pure research on the scientific basis of photography and on related subjects such as colloidal chemistry and photochemistry should be carried out, although 